\title{
Editorial
}

\section{Food insecurity: a critical public health nutrition concern}

Food security is a condition where 'all people, at all times, have physical, social and economic access to sufficient, safe and nutritious food which meets their dietary needs and food preferences for an active and healthy life,(1). However, according to the FAO, in 2015 there are still about 800 million undernourished people across the planet, of whom over $95 \%$ live in under-developed countries ${ }^{(2)}$. Even when there is no lack of food, food insecurity (FI) may manifest as low-quality diet. Low-nutrient, energydense foods are becoming increasingly accessible for economically disadvantaged segments of the population and their consumption is often associated with overweight and micronutrient deficiency ${ }^{(3,4)}$. Food shortage and poor diet are violations of the food security principles and are the causes of a significant proportion of disease burden worldwide, limiting productivity and promoting premature disability and reduced longevity.

FI is a vital issue on the public health nutrition agenda both in developing and developed countries. Therefore, measuring the magnitude of FI and evaluating the factors associated with its development are of importance for public health nutrition. The measurement of food security represents a major challenge since it should encompass the complexity of this phenomenon. According to PérezEscamilla and Segall-Corrêa ${ }^{(5)}$, experience-based FI scales are the only available direct measure of FI, which can be used for 'mapping, targeting, and understanding the determinants and consequences of food insecurity'. Most of these scales are based on the Household Food Security Supplemental Module (HFSSM) developed by the US Department of Agriculture in the mid-1990s, which is designed to capture the household food security experience and allow categorizing into different levels of $\mathrm{FI}^{(6)}$. In several countries, instruments based in the HFSSM have been developed and evaluated in order to obtain a simple, valid, reliable and low-cost method to measure household $\mathrm{FI}^{(7,8)}$. Beyond relying on the individual perception of FI and capturing its psychosocial dimensions, these scales have the advantage of offering comparable results even with the adaptations to each local socio-cultural setting and language ${ }^{(5)}$.

\section{Studies in low- and middle-income countries}

In this issue of Public Health Nutrition, the theme of FI been addressed by researchers from four continents in seven articles that explore the issue using different approaches. In Uganda, a study validated an instrument designed to assess FI at the individual level, instead of applying a household-level tool as are most HFSSM-based questionnaires. The tool was composed of questions related to food availability, selection and variety. The study included pregnant women (HIV-infected and uninfected), who tend to be at higher risk of undernutrition. The questionnaire was assessed as a good instrument to measure FI at the individual level based on agreement with other measures of socio-economic status and women's diet quality, and allowed discrimination of mild/ moderate from severe $\mathrm{FI}^{(9)}$.

In Nepal, a nationwide representative survey carried out in 2011 ascertained the association between household FI and anthropometric indicators among children under 5 years old. More than $40 \%$ of the households were moderately or severely food insecure and this unstable access to food probably compromised children's nutritional status, since FI was associated with stunting and underweight, but not with wasting. Nevertheless, food shortage may have lasted longer than the period of 12 months evaluated in the study and stunting and underweight in these children might have developed before this period, as the authors properly pointed out ${ }^{(10)}$.

In a population-based study, Schmeer et al. ${ }^{(11)}$ tested the hypothesis that mothers' economic and social resources can help to reduce FI. Evaluating households with children aged 3-11 years, the authors found a high FI rate (75\%) in a town in Nicaragua. The active participation of mothers in the domestic economy reduced the risk of FI. However, single mothers, even though financially responsible for the household, had higher risk of FI than mothers living with a partner. In a population-based study conducted in a low-income neighbourhood in Brazil, Interlenghi and Salles-Costa ${ }^{(12)}$ found that the risk of FI was reduced with an increase in social support to the family. In Mexico, the impact of the 2008 financial crisis on food security was assessed in a population-based study with cross-sectional data collected in 2008 and 2010. The study suggests that the financial crisis significantly increased the proportion of income spent on food, especially among poorer households, which may lead to higher vulnerability of families to $\mathrm{FI}^{(13)}$.

\section{Studies in high-income countries}

Developed countries are not immune to FI. In Canada, Kirk et $a l .{ }^{(14)}$ conducted a population-based study which found that $26 \%$ of households suffered some degree of FI. The diet quality of 5 th graders experiencing moderate or severe FI in the household was inferior to that of students 
living in food-secure households. Paradoxically, the reverse was observed for BMI, which was higher in the children of food-insecure households ${ }^{(14)}$. In France, $12.2 \%$ of adults evaluated in a population-based study reported some degree of FI, especially single mothers living with children. Again, the diet quality was poorer for individuals living in FI than among those reporting food security ${ }^{(15)}$.

\section{Summary and implications}

These articles may help to promote dialogue among different sectors concerned with FI and contribute to the advancement of research in this area. The theme of FI has attracted contributions from researchers using different approaches and these reports identify some of the important issues related to FI. The evaluation of FI is still a developing field of study despite the almost universal application of instruments based on the model proposed by the US Department of Agriculture ${ }^{(7)}$ and is limited by the absence of a 'gold standard' reference method. A complementary approach is the assessment of FI at the individual level proposed by Natamba et al. ${ }^{(9)}$, which is justified by the fact that within a household, some individuals may be more vulnerable to malnutrition because of their increased nutritional needs (pregnant women and children), greater physical difficulty to access food (as may be the case for elderly or disabled people) and potentially uneven distribution of available food among family members.

Among the aspects that seem to increase the probability of FI, lack of social support appears to be important, especially among women in vulnerable social situations, such as single mothers and during pregnancy. Furthermore, the instability in food supply at home is associated with various adverse outcomes including poorer nutritional status of young children, high BMI among adolescents, the proportion of family budget spent on food and diet quality. Beyond the amount of food available in the household, FI may impact food consumption by favouring the selection of energy-dense, nutrient-poor foods, like sweets and sugarsweetened beverages, over foods of nutritional quality, particularly fruits, vegetables and fish. Such choices may increase the risk of excess weight gain and other diet-related health problems, suggesting it would be important to address food security before implementing other programmes to improve nutrition in vulnerable populations.

Rosangela A Pereira Associate Editor

Allison Hodge Deputy Editor

\section{References}

1. Food and Agriculture Organization of the United Nations (2003) Trade Reforms and Food Security - Conceptualizing the Linkages. Rome: FAO.

2. Food and Agriculture Organization of the United Nations, International Fund for Agricultural Development \& World Food Programme (2015). The State of Food Insecurity in the World 2015. Meeting the 2015 International Hunger Targets: Taking Stock of Uneven Progress. Rome: FAO.

3. Burns C (2004) A review of the literature describing the link between poverty, food insecurity and obesity with specific reference to Australia. http://secondbite.org/sites/default/files/ A_review_of_the_literature_describing_the_link_between poverty_food_insecurity_and_obesity_w.pdf (accessed June 2015).

4. Popkin BM, Adair LS \& Ng SW (2012) Global nutrition transition and the pandemic of obesity in developing countries. Nutr Rev 70, 3-21.

5. Pérez-Escamilla R \& Segall-Corrêa AM (2008) Food insecurity measurement and indicators. Rev Nutr 21, Suppl., 15S-26S; available at http://www.scielo.br/scielo.php?script=sci_ arttext\&pid $=$ S1415-52732008000700003\&lng $=$ en.

6. Radimer KL, Olson CM \& Campbell CC (1990) Development of indicators to assess hunger. J Nutr 120, 1544-1548.

7. Melgar-Quinonez H \& Hackett M (2008) Measuring household food security: the global experience. Rev Nutr 21, Suppl., 27S-37S; available at http://www.scielo.br/scielo.php?script=s ci_arttext\&pid=S1415-52732008000700004\&lng=en.

8. Coates J, Frongillo EA, Rogers BL et al. (2006) Commonalities in the experience of household food insecurity across cultures: what are measures missing? J Nutr 136, issue 5, 1438S-1448S.

9. Natamba BK, Kilama H, Arbach A et al. (2015) Reliability and validity of an individually focused food insecurity access scale for assessing inadequate access to food among pregnant Ugandan women of mixed HIV status. Public Health Nutr 18, 2895-2905.

10. Sreeramareddy CT, Ramakrishnareddy N \& Subramaniam M (2015) Association between household food access insecurity and nutritional status indicators among children aged $<5$ years in Nepal: results from a national, crosssectional household survey. Public Health Nutr 18, 2906-2914.

11. Schmeer KK, Piperata BA, Rodríguez AH et al. (2015) Maternal resources and household food security: evidence from Nicaragua. Public Health Nutr 18, 2915-2924.

12. Interlenghi GS \& Salles-Costa R (2015) Inverse association between social support and household food insecurity in a metropolitan area of Rio de Janeiro, Brazil. Public Health Nutr 18, 2925-2933.

13. Vilar-Compte M, Sandoval-Olascoaga S, Bernal-Stuart A et al. (2015) The impact of the 2008 financial crisis on food security and food expenditures in Mexico: a disproportionate effect on the vulnerable. Public Health Nutr 18, 2934-2942.

14. Kirk SFL, Kuhle S, McIsaac J-LD et al. (2015) Food security status among grade 5 students in Nova Scotia, Canada and its association with health outcomes. Public Health Nutr 18, 2943-2951.

15. Bocquier A, Vieux F, Lioret S et al. (2015) Socio-economic characteristics, living conditions and diet quality are associated with food insecurity in France. Public Health Nutr 18, 2952-2961. 